\title{
Educação Matemática na Educação Profissional de Nível Médio: análise sobre possibilidades de abordagens interdisciplinares
}

\author{
Mathematical Education in Mid-level Professional Education: analysis of \\ opportunities for interdisciplinary approaches
}

\author{
Harryson Júnio Lessa Gonçalves* \\ Célia Maria Carolino Pires ${ }^{* *}$
}

\begin{abstract}
Resumo
No presente artigo nosso objetivo é ampliar a discussão sobre a educação matemática de alunos da Educação Profissional de Nível Médio no Brasil (EPTNM), focalizando a questão da interdisciplinaridade, apontada em documentos oficiais como um dos eixos organizadores dos currículos para essa modalidade de ensino. Estudos nesse campo justificam-se, tanto pela dimensão que essa modalidade vem tomando no sistema educacional brasileiro, como pela carência de investigações específicas na área de Educação Matemática sobre EPTNM. Nossa investigação orienta-se pelas questões: a adoção de uma perspectiva de organização curricular interdisciplinar pode contribuir para a articulação entre a formação profissional técnica e a formação mais acadêmica como é colocada para o Ensino Médio? Quais suas potencialidades para a constituição de aprendizagens mais significativas de conteúdos matemáticos nessa modalidade de ensino? Avaliamos que a superficialidade com que o tema da interdisciplinaridade tem sido tratado e a falta de sua contextualização no âmbito das demais pesquisas em Educação Matemática são alguns dos fatores da não implementação da ideia com sucesso. Nesse sentido, neste artigo, retomamos a contribuição de diferentes autores que investigam o tema e incluímos proposições no sentido de explorar a Etnomatemática e a Modelagem como possibilidades de enriquecimento curricular da EPTNM, articulando diferentes áreas do conhecimento e contextualizando a matemática na realidade do mundo do trabalho.
\end{abstract}

Palavras-chave: Educação Profissional. Currículos de Matemática. Interdisciplinaridade. Modelagem Matemática.

\begin{abstract}
In this article we aim to broaden the discussion about mathematical education of students of Middle Level Professional Education in Brazil (EPTNM), focusing on the issue of interdisciplinarity, emphasized in official documents as one of the organizing axes of the curriculum for this type of education. Studies in this field are justified by the growth of this modality in the Brazilian educational system, as well as the lack of specific investigations in the field of Mathematics Education about it. Our research is guided by the questions: Can the adoption of an interdisciplinary approach to organizing the curriculum contribute to building links between

\footnotetext{
* Doutor em Educação Matemática pela Pontifícia Universidade Católica de São Paulo (PUC/SP). Professor da Universidade Estadual Paulista "Júlio de Mesquita Filho", campus de Ilha Solteira, SP, Brasil. Endereço para correspondência: Departamento de Biologia de Zootecnia, Passeio Monção, n. ${ }^{\circ}$ 226, Zona Norte, CEP: $15385-$ 000, Ilha Solteira, SP, Brasil. E-mail: harryson@bio.feis.unesp.br

** Doutora em Educação pela Universidade de São Paulo (USP). Professora do Programa de Estudos PósGraduados em Educação Matemática da Pontifícia Universidade Católica de São Paulo (PUC/SP), São Paulo, SP, Brasil. Endereço para correspondência: Rua Marquês de Paranaguá, 111, Consolação, CEP: 01303-050, São Paulo, SP, Brasil. E-mail: celia@pucsp.br
} 
technical professional education and the more academic education characteristic of Middle Level education? What are its potentialities for promoting more meaningful learning of mathematical content in this type of education? We conclude that the superficiality with which the theme of interdisciplinarity has been handled, and the lack of contextualization in other research related to it in mathematics education, are some of the reasons for not implementing the idea successfully. In this article, we discuss the contribution of different authors who research the theme and include proposals to explore Ethnomathematics and Modeling as possibilities for curriculum enrichment of the EPTNM, linking different areas of knowledge and contextualizing math in the reality of the world of work.

Keywords: Professional Education. Math Curriculum. Interdisciplinarity. Mathematical Modeling.

\section{A Educação Profissional no Brasil: crescimento, desafios e demandas de investigações}

O Ministério da Educação divulgou que, segundo o Censo Escolar de 2010, as matrículas na Educação Profissional cresceram 74,9\% entre 2002 e 2010. Em 2010, o país tinha 1,1 milhão de jovens na educação profissional, enquanto que, em 2002, estes somavam 652.073. No mesmo período, o ensino público, em específico da Rede Federal de Educação Profissional, Científica e Tecnológica (RFEPCT), passou de 77.190 alunos para 165.355, o que representa crescimento de $114 \%$. A trajetória de expansão da Educação Profissional também pode ser vista entre 2007 e 2010. Em 2007, as matrículas eram 780.162; ao alcançar 1.140.388, neste ano, o crescimento foi de $46 \%$ no intervalo (BRASIL, 2010).

Mesmo assim, notícias frequentemente divulgadas na mídia apontam a falta de profissionais habilitados em várias áreas de atuação como um obstáculo para as empresas. Temos como exemplo a pesquisa realizada pela Confederação Nacional da Indústria com 1,6 mil empresas de todo o País (BRASIL, 2011). Os resultados apontaram que, de cada dez indústrias, sete estão com problemas para conseguir mão de obra qualificada. Em muitos casos, o trabalhador tem dificuldade para se adaptar, por exemplo, a uma nova máquina ou a um processo de produção mais moderno. O problema ocorre em todos os setores industriais, com empresas de todos os tamanhos e com todo tipo de trabalhador, desde o operador de máquina, até técnicos e pessoas com nível superior. Cursos de treinamento dentro da fábrica são a principal medida que as indústrias estão adotando para contornar o problema, mas os resultados estão demorando a surgir. E, segundo os empresários que participaram da referida pesquisa, isso compromete a produtividade e torna a indústria brasileira menos competitiva. $\mathrm{O}$ estudo aponta que a origem do problema está na baixa qualidade da Educação Básica, que acaba acompanhando a pessoa durante toda a sua vida profissional.

No Brasil, a Educação Profissional abrange os seguintes cursos: (a) Formação Inicial e Continuada ou Qualificação Profissional; (b) Educação Profissional Técnica de Nível Médio 
(EPTNM); (c) Educação Profissional Tecnológica (graduação e pós-graduação). Ressalta-se ainda que a EPTNM, foco deste trabalho, tem como objetivo preparar o aluno para o exercício de profissões técnicas. Esta pode ser desenvolvida nas seguintes formas: (a) Integrada oferecida somente a quem já tenha concluído o Ensino Fundamental, sendo o curso planejado de modo a conduzir o aluno à habilitação profissional técnica de nível médio, na mesma instituição de ensino, efetuando-se matrícula única para cada aluno, garantindo assim a formação geral do Ensino Médio e a formação profissional técnica; (b) Concomitante oferecida a quem está ingressando no Ensino Médio ou já o esteja cursando, efetuando-se matrículas distintas para cada curso, e podendo ocorrer na mesma ou em diferentes instituições de ensino; (c) Subsequente - destinada a quem já tenha concluído o Ensino Médio. (BRASIL, 1996).

No âmbito oficial, as Diretrizes Curriculares Nacionais para a Educação Profissional de Nivel Técnico apresentam formulações para a organização curricular nessa modalidade, como podemos observar em alguns artigos do documento:

Art. 3. ${ }^{\circ}$ São princípios norteadores da educação profissional de nível técnico os enunciados no artigo $3 .^{\circ}$ da LDB, mais os seguintes:

I - independência e articulação com o Ensino Médio;

II - respeito aos valores estéticos, políticos e éticos;

III - desenvolvimento de competências para a laborabilidade;

IV - flexibilidade, interdisciplinaridade e contextualização;

$\mathrm{V}$ - identidade dos perfis profissionais de conclusão de curso;

VI - atualização permanente dos cursos e currículos;

VII - autonomia da escola em seu projeto pedagógico.

Art. $4 .^{\circ}$ São critérios para a organização e o planejamento de cursos:

I - atendimento às demandas dos cidadãos, do mercado e da sociedade;

II - conciliação das demandas identificadas com a vocação e a capacidade institucional da escola ou da rede de ensino. [...]

Art. $6 .^{\circ}$ Entende-se por competência profissional a capacidade de mobilizar, articular e colocar em ação valores, conhecimentos e habilidades necessários para o desempenho eficiente e eficaz de atividades requeridas pela natureza do trabalho.

Parágrafo único. As competências requeridas pela educação profissional, considerada a natureza do trabalho, são as:

I - competências básicas, constituídas no Ensino Fundamental e Médio;

II - competências profissionais gerais, comuns aos técnicos de cada área;

III - competências profissionais específicas de cada qualificação ou habilitação (BRASIL, 1999b, paginação irregular, grifos nossos).

No entanto, além de muito genéricas, essas diretrizes de modo frequente são pouco debatidas nas instituições com intuito de buscar parâmetros de qualidade na formação laboral de profissionais técnicos.

Outro problema identificado no âmbito das pesquisas em Educação Matemática, quando se buscam trabalhos que discutam a temática da Educação Profissional, é o fato de 
esse tema ser praticamente inexplorado, embora seja um campo de pesquisa fecundo para educadores matemáticos.

Iniciamos nossa investigação a partir de uma análise das marcas e trajetórias da Educação Profissional no Brasil, em que são visíveis os encontros e desencontros entre a Educação Profissional e a Educação Básica. Também é nítida sua importância para a sociedade industrializada. Ora destinada aos menos favorecidos, ora atendendo a alunos que buscam os cursos por sua qualidade, mas sem aspirações de formação profissional, a EPTNM mostra-se como um desafio às instituições de ciência e tecnologia na busca por uma identidade própria na formação de seus estudantes.

Em um movimento de idas e vindas, percebemos que: (a) ora a Educação Profissional estava completamente distanciada da formação escolar; (b) ora fazia-se presente como uma rede paralela à da educação primária e secundária, utilizando-se das disciplinas propedêuticas para aprendizagem dos ofícios (leis orgânicas e Lei 4.024/1961); (c) outras vezes a rede fundia-se completamente com a educação secundária, tornando-se compulsoriamente profissionalizante (Lei 5.692/1971); (d) atualmente, pela Lei 9.394/1996, é uma rede paralela à rede regular, porém garantindo tanto uma formação propedêutica quanto profissionalizante. Nesse contexto, consideramos que cabe também à Educação Matemática uma apreensão/compreensão desses movimentos visando à criação de propostas que rediscutam o próprio papel da Matemática na organização e desenvolvimento curricular da educação profissional.

Essa foi a motivação da escolha da EPTNM como tema de investigação e que se inseriu no Grupo de Pesquisa "Desenvolvimento Curricular em Matemática e Formação de Professores", especificamente no Projeto intitulado "Construção de Trajetórias Hipotéticas de Aprendizagem e implementação de inovações curriculares em Matemática no Ensino Médio", desenvolvido de 2007 a $2012^{1}$.

O projeto foi realizado por seis doutorandos e quinze mestrandos, que se orientaram por algumas referências teóricas comuns e que tinham como motivação compreender o processo de construção e desenvolvimento de propostas de apoio à inovação curricular na área de Matemática, considerando alguns princípios apresentados nas Diretrizes e Parâmetros Curriculares para o Ensino Médio, focalizando o papel dos professores nesse processo.

\footnotetext{
${ }^{1}$ O Projeto foi proposto e desenvolvido por dois pesquisadores, no âmbito do Programa de Estudos PósGraduados em Educação Matemática da Pontifícia Universidade Católica de São Paulo, Profa ${ }^{a}$ Dra ${ }^{a}$. Célia Maria Carolino Pires e Prof. Dr. Armando Traldi Júnior.
} 
Nossa investigação baseia-se em análise de currículos prescritos e currículos planejados por professores de escola que oferece EPTNM. Os documentos examinados foram: Diretrizes Curriculares Nacionais para o Ensino Médio, Diretrizes Curriculares para Educação Profissional Técnica, Parâmetros Curriculares Nacionais para o Ensino Médio; Projetos pedagógicos de cursos técnicos integrados do Instituto Federal de Educação, Ciência e Tecnologia de São Paulo (IFSP).

Nos currículos analisados, buscou-se compreender o papel da Matemática diante da formação para a laboralidade e a formação geral de Ensino Médio, bem como as orientações referentes à interdisciplinaridade como eixo norteador do currículo ${ }^{2}$. Justificamos nosso estudo pela possibilidade de contribuir para uma análise crítica de currículos de Matemática na EPTNM, diante de uma perspectiva interdisciplinar, promovendo, assim, a formação de sujeitos com uma percepção crítica da realidade, atrelada à relação que irá estabelecer com o mundo do trabalho.

No Grupo de Pesquisa discutimos que o conceito de currículo tem variado muito de acordo com a época, os contextos ou os modelos teóricos. Grundy (1987) afirma que “o currículo não é um conceito, mas uma construção cultural. Isto é, não se trata de um conceito abstrato que tenha algum tipo de existência fora e previamente à experiência humana. É, antes, um modo de organizar uma série de práticas educativas" (apud SACRISTÁN, 2000, p. 14).

Assim, é possível entender o currículo a partir de decisões pedagógicas e educacionais para a escola, pois um currículo pressupõe, sempre, uma resposta às perguntas: $o$ que ensinar?, como ensinar?, por que ensinar?, onde ensinar?, quando ensinar?, considerandose, para tanto, que os condicionantes administrativos, institucionais e pedagógicos afetam o desenvolvimento curricular, além das determinações sociais e políticas.

Conforme aponta Sacristán, o currículo se caracteriza como objeto que se constrói a partir do processo de configuração, implantação, concretização e expressão em determinadas práticas pedagógicas e na sua avaliação, como resultado das diversas intervenções que nele operam. $\mathrm{O}$ autor amplia esse entendimento de currículo, em sua dimensão prática, como "projeto seletivo de cultura, cultural, social, político e administrativamente condicionado, que

\footnotetext{
${ }^{2} \mathrm{O}$ detalhamento dos referidos currículos poderão ser encontrados na tese de doutoramento de Gonçalves (2012).
} 
preenche a atividade escolar e que se torna realidade dentro das condições da escola tal como das condições contra configurada" (2000, p. 35).

\section{Interdisciplinaridade como eixo norteador da educação profissional}

Em diferentes documentos oficiais, identificamos a proposta de tomar a interdisciplinaridade como um eixo norteador da Educação Profissional.

As Diretrizes Curriculares Nacionais para o Ensino Médio (Resolução CNE/CEB 03, de 26 de junho de 1998, e as alterações e atualizações feitas pelas Resoluções CNE/CEB 01/2005, 04/2005 e 04/2006) apontam a interdisciplinaridade como princípio pedagógico para a estruturação dos currículos escolares, por conseguinte como elemento essencial para construção de uma pedagogia de qualidade.

As Diretrizes Curriculares Nacionais para a Educação Profissional de Nível Técnico (Resolução CNE/CEB 04/1999 e as alterações feitas pelas Resoluções CNE/CEB 01/2005 e 04/2005) apontam formação que garanta uma atuação laboral com qualidade, estabelecendo a interdisciplinaridade como um dos princípios norteadores da organização e desenvolvimento curricular.

Os Parâmetros Curriculares Nacionais de Ensino Médio (BRASIL, 1999c) tomam a interdisciplinaridade e a contextualização como ponto de partida à necessidade de superação de práticas pedagógicas descontextualizadas e compartimentadas, considerando-as como eixos viabilizadores da transposição didática do conhecimento no Ensino Médio, visando à ressignificação dos saberes escolares em atendimento às demandas da consolidação do estado democrático, das novas tecnologias e das mudanças na produção de bens, serviços e conhecimentos, possibilitando a integração do aluno ao mundo contemporâneo nas dimensões fundamentais da cidadania e do trabalho.

Em que pese a relevância atribuída à interdisciplinaridade nos currículos prescritos de EPTNM, nas análises de projetos curriculares na instituição pesquisada, essa perspectiva não se evidencia. Para entender melhor a problemática em que se insere a interdisciplinaridade, consideramos importante buscar referências teóricas relativas a esse conceito para orientar nossas análises curriculares referentes à EPTNM e que trazemos, de forma sintetizada, na sequência. 
Na revisão da literatura observa-se logo que não há definição unívoca do conceito de interdisciplinaridade. Ou seja, o termo interdisciplinaridade é fruto de significativas flutuações: "da simples cooperação de disciplinas ao intercâmbio mútuo e integração recíproca ou, ainda, a uma integração capaz de romper a estrutura de cada disciplina e alcançar uma axiomática comum" (POMBO, 1994, p. 10). Apesar da instabilidade conceitual, a palavra possui uma utilização muito ampla e em diversos contextos; tomem-se como exemplos:

(a) Contexto Epistemológico - práticas de transferência entre áreas de conhecimento (disciplinas) e seus pares.

(b) Contexto Pedagógico - questões do ensino, práticas escolares, transferência de conhecimentos entre professores e alunos, que têm lugar no interior do currículo escolar, dos métodos de trabalho, das novas tecnologias, de estruturas organizativas de ensino.

(c) Contexto Midiático - prática utilizada pelos meios de comunicação para discutir um determinado problema; juntam-se várias pessoas de diferentes perspectivas que, em conjunto, discutem a temática.

(d) Contexto Empresarial e Tecnológico - processo expedito de gestão e decisão - o caso da produção técnica e tecnológica ou equipes de concepção, planificação e produção de objetos.

Assim, corrobora-se que uma palavra está gasta, por vezes vazia, visto que ela é utilizada em diversos contextos e dificilmente se consegue definir; porém, muitos reivindicam sua utilização.

Outros autores comprovam a referida situação:

[...] o uso indiscriminado do termo no ensino, na pesquisa, no exercício
profissional, nos meio de comunicação, nos congressos ou seminários, nos subtítulos
de obras científicas, aponta para múltiplos significados e, em consequência, para
nenhum significado comum aceito pela comunidade de professores e pesquisadores
(PAVIANI, 2004, p. 15).

Embora consideremos de certo modo natural essa polissemia, o fato a destacar é o de que se observa também uma certa banalização impregnada nas narrativas de profissionais diversos, incluindo-se educadores, para caracterizar sua prática como interdisciplinar. É como se fosse uma chancela de qualidade do trabalho, mas que traz uma simplificação conceitual. 
Alguns autores apontam que a interdisciplinaridade e suas variações (multi, pluri e trans) já haviam sido tratadas há algum tempo na história do conhecimento e da ciência. Tome-se como exemplo Platão, que foi um dos primeiros pensadores a entrever a necessidade de uma ciência unificada, propondo que essa tarefa fosse desempenhada pela Filosofia (SANTOMÉ, 1998).

Carlos (2007) explora a ideia:

Os sofistas gregos ainda foram responsáveis pelo estabelecimento de uma enkuklios Paideia, uma espécie de currículo de ensino que proporcionava aos alunos um exame geral das disciplinas constitutivas da ordem intelectual e que, posteriormente, na época medieval, manifestou-se através da divisão do conhecimento em dois grandes segmentos: o trivium (gramática, retórica e dialética) e o quadrivium (aritmética, geometria, astronomia e música), que juntos representaram o papel de programas pioneiros de um ensino integrado que agrupa os âmbitos do conhecimento tradicionalmente denominados letras e ciências (CARLOS, 2007, p. 24).

Ubiratan D’Ambrosio (2005) ilustra outra situação quando resgata na obra Histoire de l'Académie des Sciences, de Bernard le Bovier de Fontenelle, de 1699, então secretário da Academia de Ciências de Paris, o trecho:

Até agora a Academia considera a natureza só por parcelas... Talvez chegará o momento em que todos esses membros dispersos (as disciplinas) se unirão em um corpo regular; e se são como se deseja, juntar-se-ão por si mesmas de certa forma (1699, p. XIX, apud D'AMBROSIO, 2005, p. 103).

Contudo, somente a partir do século 20 foi possível identificar um efetivo aparecimento do termo interdisciplinaridade em documentos e registros históricos com uma aparente aproximação conceitual do termo.

O movimento de interdisciplinaridade surge na Europa, principalmente na França e na Itália, em meados da década de 1960 (causa ou consequência, não é o caso de aqui se discutir o lado mais importante da questão, acreditamos que ambos), época em que se insurgem os movimentos estudantis, reivindicando um novo estatuto de universidade e de escola (FAZENDA, 2011, p. 18).

Paviani (2004) complementa que a interdisciplinaridade surge como:

[...] solução para o problema de fragmentação do conhecimento, da perda de visão de conjunto da realidade e de resultados eficazes diante dos problemas. Para alcançar seus objetivos, ela não pode ser deduzida a uma simples colaboração ou intercâmbio entre pesquisadores e professores. Ela envolve desde os aspectos lógicos e epistemológicos do conhecimento até a aplicação de conhecimento de uma disciplina em outra. Sua missão é a de conservar e mediar as contradições do conhecimento nas esferas pedagógico-epistemológicas e políticas socioinstitucionais (PAVIANI, 2004, p. 17). 
Segundo Mangini e Mioto (2009), em dezembro de 1969, um relatório do Centro para Pesquisa e Inovação do Ensino (CERI) ${ }^{3}$ apresentou-se como referência para a construção da categoria interdisciplinaridade. Esse relatório, que visava distinguir as estruturas institucionais das universidades e seus programas de estudo, apontou uma imprecisão terminológica, causada pelo preconceito referente às questões de integração entre os saberes e pelo desconhecimento de pressupostos básicos relacionados à interdisciplinaridade.

O CERI, na tentativa de esclarecer esses problemas da terminologia, convoca Guy Michaud e inicia uma reflexão epistemológica para conceituar essa terminologia, diferenciando-as a partir de quatro níveis: multidisciplina, pluridisciplina, interdisciplina e transdisciplina. Em fevereiro de 1970, ocorre o Seminário sobre Interdisciplinaridade e Transdisciplinaridade, evento que reuniu representantes de países-membros da OCDE - o grupo foi composto por 21 especialistas, dentre eles Andre Lichnerowicz, Asa Briggs, Eric Jantsch, Georges Gusdorf, Heinz Heckhausen, Jean Piaget, Leo Apostel e Marcel Boisot. Tendo como referência os estudos desse grupo, no período de 7 a 12 de setembro do mesmo ano, em Nice na França, ocorreu o Seminário Internacional sobre Pluridisciplinaridade e Interdisciplinaridade nas Universidades, conhecido como Congresso de Nice - organizado pelo CERI e pelo Ministério da Educação francês. Esse evento visava esclarecer os conceitos de multidisciplinaridade, pluridisciplinaridade, interdisciplinaridade e transdisciplinaridade a partir de uma reflexão epistemológica (MANGINI; MIOTO, 2009; JAPIASSU, 1976).

Outros eventos foram realizados com esse mesmo propósito, contando, inclusive, com o patrocínio da OCDE e da Organização das Nações Unidas para a Educação, Ciência e Cultura (Unesco). Mangini e Mioto apontam que

\begin{abstract}
As contribuições de especialistas como Jantsch, Heckhausen, Piaget, Michaud, nos eventos relacionados, conformaram as bases conceituais da interdisciplinaridade. Contudo, apesar das semelhanças entre alguns grupos de estudiosos não se chegou a uma definição consensual (MANGINI; MIOTO, 2009, p. 208).
\end{abstract}

Hilton Japiassu (1976), um dos pioneiros da discussão sobre a interdisciplinaridade no Brasil, motivado pelas discussões do Congresso de Nice, foi o responsável pela introdução da temática no contexto brasileiro por meio do livro Interdisciplinaridade e patologia do saber. Para o autor, a interdisciplinaridade é considerada como estratégica superação do problema da

\footnotetext{
${ }^{3}$ O CERI tem como objetivo encorajar e desenvolver a cooperação entre os países-membros da Organização para a Cooperação e Desenvolvimento Econômico (OCDE) em pesquisa e inovação no ensino (MANGINI; MIOTO, 2009). A OCDE é uma organização internacional (34 países-membros) que possui a missão de promover políticas que melhorem o desenvolvimento econômico e o bem-estar das pessoas em todo o mundo. Disponível em: <http://www.oecd.org/about/>.
} 
disciplinaridade, que, para ele, é vista como patologia que deve ser sanada por meio de uma ação interdisciplinar.

O autor aponta que a disciplina ou disciplinaridade é a exploração progressiva científica de uma determinada área ou domínio homogêneo de estudo, em que esta deverá definir e estabelecer suas fronteiras constituintes - estas fronteiras é que irão determinar seus objetos formais e materiais, seus sistemas e métodos, seus conceitos e teorias.

Segundo Ubiratan D'Ambrosio,

[...] as disciplinas dão origem a métodos específicos para conhecer objetos de estudo bem definidos. Os métodos e os resultados assim obtidos, que se referem a questionamentos claramente identificados, constituem um corpo nomeado de conhecimento (D'AMBROSIO, 2005, p. 103).

Falar em interdisciplinaridade é se referir à integração dessas disciplinas; embora entendendo disciplina como sinônimo de ciência, o termo é mais empregado para designar o ensino de uma dada ciência.

Para Japiassu, a interdisciplinaridade caracteriza-se pela intensidade das trocas entre especialistas e pelo grau de real integração das disciplinas no interior de um mesmo projeto de pesquisa. Ou seja, torna-se possível a complementaridade dos conceitos, métodos, dos axiomas e das estruturas sobre as quais se fundam as diversas práticas científicas. Para esse autor,

O que podemos entender por disciplina e por disciplinaridade é essa progressiva exploração científica especializada numa certa área do domínio homogêneo do estudo. Uma disciplina deverá, antes de tudo, estabelecer e definir suas fronteiras constituintes. Fronteiras estas que irão determinar seus objetos materiais e formais, seus métodos e sistemas, seus conceitos e teorias (JAPIASSU, 1976, p. 61).

Assim, mesmo que nas ciências naturais ocorra um amplo acordo para compreensão dos fenômenos de estudo, respeitando e harmonizando as respectivas fronteiras do conhecimento sobre o mundo natural, nas ciências humanas, essas fronteiras do conhecimento dificultam a compreensão do mundo antropossocial em razão de sua complexidade - gerando aí uma patologia do saber.

Uma disciplina qualquer, cujo estatuto permanece fixo uma vez por todas, mesmo que pretenda interessar-se pelo homem, jamais poderá encontrá-lo, sempre fornecendo dele um conhecimento parcial e truncado, já que aborda os fatos humanos sob o ângulo de um determinismo particular, extremamente restritivo (JAPIASSU, 1976, p. 62). 
Desse modo, para o autor, a interdisciplinaridade apresenta-se nas ciências humanas como esforço de reconstituição da unidade do objeto que a fragmentação dos métodos, indevidamente, pulveriza.

Concordamos com Japiassu (1976) quando ele afirma que o maior problema reside no conceito de interdisciplinaridade, pois o próprio conceito varia não apenas no nome, mas também naquilo que ele significa (conteúdo). Assim, Japiassu, com base em Heckhausen, apresenta as modalidades de interdisciplinaridade, em ordem de "maturidade":

(a) Interdisciplinaridade Heterogênea - tipo de enfoque de caráter enciclopédico, combinando programas diferentemente dosados.

(b) Pseudointerdisciplinaridade - diversas tentativas de utilização de instrumentos conceituais e de análise, considerados epistemologicamente "neutros", na tentativa de associar disciplinas, como um elemento comum. O emprego desses instrumentos comuns não é suficiente para conduzir a um empreendimento interdisciplinar e é por isso que esse tipo de colaboração pode ser tachado de falso interdisciplinar.

(c) Interdisciplinaridade Auxiliar - uma disciplina toma de empréstimo de outra seus métodos ou procedimentos. Em alguns casos, este tipo de interdisciplinaridade não ultrapassa o domínio da ocasionalidade e das situações provisórias, em outros, pode ser mais duradoura, na medida em que uma disciplina se vê constantemente forçada a empregar métodos da outra.

(d) Interdisciplinaridade Compósita - reunião de várias especialidades para encontrar soluções técnicas, tendo em vista resolver determinados problemas, geralmente grandes e complexos como guerras, fome etc. Verifica-se que é uma conjugação de disciplinas por aglomeração, cada uma dando a sua contribuição, mas guardando a autonomia e a integridade de seus métodos, de seus conceitos-chave e de sua epistemologia.

(e) Interdisciplinaridade Unificadora - coerência bastante estreita do domínio de estudos das disciplinas, havendo certa integração de seus níveis de integração teórica e dos métodos correspondentes. Tome-se como exemplo: Biologia + Física = Biofísica.

Ivani Fazenda, educadora brasileira pioneira no estudo da temática no contexto educacional brasileiro, toma como base os trabalhos de Japiassu e dá prosseguimento ao tema no contexto da organização e desenvolvimento curricular. Logo, marca o caráter problemático 
da disciplinaridade no campo educacional brasileiro e dispõe de uma pedagogia interdisciplinar. Para fins didáticos, a autora divide o seu movimento no cenário educacional brasileiro em três perspectivas: (a) anos 70 - busca por uma explicação filosófica; (b) anos 80 - busca por uma diretriz sociológica; (c) anos 90 - busca por um projeto (FAZENDA, 2011).

Fazenda (2011) também salienta a impossibilidade de construção de uma absoluta, única e geral teoria da interdisciplinaridade, mas que é necessário o desvelamento ou a busca do percurso teórico pessoal de cada pesquisador que se aventurou a tratar as questões desse tema.

Na busca pela definição do conceito de interdisciplinaridade, a autora preconiza que a interdisciplinaridade:

\footnotetext{
[...] é uma atitude de abertura, não preconceituosa, onde todo o conhecimento é igualmente importante. Pressupõe o anonimato, pois o conhecimento pessoal anulase frente ao saber universal. É uma atitude coerente, que supõe uma postura única frente aos fatos, é na opinião crítica do outro que fundamenta-se a opinião particular. Somente na intersubjetividade, num regime de copropriedade, de interação, é possível o diálogo, única condição de possibilidade da interdisciplinaridade. Assim sendo, pressupõe uma atitude engajada, um comprometimento pessoal (FAZENDA, 1996, p. 8).
}

Ou seja, a partir de uma atitude do sujeito de humildade e ousadia no desejo de inovar, criar e ir além se pode constituir uma ação pedagógica interdisciplinar, mediante uma filosofia do sujeito.

Para Fazenda (2008), pensar a interdisciplinaridade como junção de disciplinas é pensar o currículo apenas na formação de sua grade, porém, ao se definir interdisciplinaridade como atitude de ousadia e busca perante o conhecimento, cabe pensar aspectos que envolvem a cultura do lugar onde os professores se formam. Desse modo, somente torna-se possível falar sobre o professor e sua formação quando ampliamos a análise do campo conceitual da interdisciplinaridade, surgindo, aí, a possibilidade de explicitação de seu espectro: (a) Epistemológico - Para que quero formar este ser? (b) Ontológico - Que ser queremos formar? (c) Praxeológico - Quais os valores implícitos quero formar neste ser?

A transposição de certas barreiras, que se apresentam como obstáculos, permitirão o surgimento de um ensino interdisciplinar, por meio de novos métodos, novos objetivos e de uma nova pedagogia, cuja formulação primeira é a supressão do monólogo e a instauração de uma nova dialógica. Para tanto, faz-se necessária a eliminação das barreiras entre as disciplinas e entre as pessoas que pretendem desenvolvê-las (FAZENDA, 2002). 
Segundo Fazenda (1996; 2002), apresentam-se os seguintes obstáculos para o desenvolvimento de uma prática pedagógica interdisciplinar:

1) Obstáculos Epistemológicos e Institucionais - a interdisciplinaridade torna-se possível quando se respeitam os princípios de cada disciplina, tendo-se em vista um conhecer melhor; nesse sentido, a eliminação das barreiras entre as disciplinas exigiria a quebra da rigidez das estruturas institucionais que, de certa forma, reforçam o capitalismo epistemológico das diferentes ciências.

2) Obstáculos Psicossociológicos e Culturais - o desconhecimento do real significado do projeto interdisciplinar, a falta de formação específica, a acomodação à situação estabelecida e o medo de perder prestígio pessoal impedem a montagem de uma equipe especializada que parta em busca de uma linguagem comum.

3) Obstáculos Metodológicos - a instauração de uma metodologia interdisciplinar postularia um questionamento das formas de desenvolvimento do conteúdo das disciplinas, em função do tipo de indivíduo que se pretende formar, bem como uma postura com respeito à reflexão de todos os elementos indicados.

4) Obstáculos quanto à Formação - na interdisciplinaridade, passa-se de uma relação pedagógica, baseada na transmissão do saber de uma disciplina ou matéria, a uma relação dialógica, em que a posição é de construção do conhecimento. É necessário que, ao lado de uma formação teórica, se estabeleça um treino constante no trabalho interdisciplinar.

5) Obstáculos Materiais - para a efetivação da interdisciplinaridade, é primordial um planejamento de espaço e tempo, bem como uma previsão orçamentária adequada.

Fazenda (2002) considera a importância da articulação da interdisciplinaridade nos universos epistemológico e pedagógico como:

(a) meio de conseguir uma melhor formação geral, pois somente um enfoque interdisciplinar pode possibilitar certa identificação entre o vivido e o estudado, desde que o vivido resulte da inter-relação de múltiplas e variadas experiências;

(b) meio de atingir uma formação profissional, pois permite a abertura de novos campos do conhecimento e novas descobertas; 
(c) incentivo à formação de pesquisadores e de pesquisas, pois o sentido das investigações interdisciplinares é reconstruir a unidade dos objetos que a fragmentação dos métodos separou e, com isso, permitir a análise das situações globais, dos limites de seu próprio sistema conceitual e o diálogo entre as disciplinas;

(d) condição para uma educação permanente, posto que por meio da intersubjetividade, característica essencial da interdisciplinaridade, será possível a troca contínua de experiências;

(e) forma de compreender e modificar o mundo, pois, como o homem é agente e paciente da realidade do mundo, torna-se necessário um conhecimento efetivo dessa realidade em seus múltiplos aspectos;

(f) superação da dicotomia ensino-pesquisa, pois, nesse novo enfoque pedagógico, a pesquisa se constitui na única forma possível de aprendizagem.

Fazenda (2002) acrescenta ainda que, articulando os universos epistemológico e pedagógico, a interdisciplinaridade não pode ser entendida como uma panaceia que garantirá um adequado ensino, ou um saber unificado, mas um ponto de vista que permitirá uma reflexão aprofundada, crítica e salutar sobre o funcionamento do ensino. Contudo, a autora afirma que as práticas interdisciplinares podem gerar práticas vazias ou meras proposições ideológicas, impedindo o questionamento de problemas reais, caso seus participantes permaneçam em um jogo de integração, descuidando-se de questionar a realidade a que pertencem e o papel que nela ocupam.

Para Machado (2000), a interdisciplinaridade tem sido uma palavra-chave na discussão da organização do trabalho acadêmico e escolar, pois supera uma fragmentação crescente dos objetos do conhecimento nas diversas áreas, gerando uma visão de conjunto, e facilita para o processo de ensino-aprendizagem o enquadramento de fenômenos que ocorrem fora da escola que não se contextualizam no âmbito de uma única disciplina.

Pires (2004), em suas considerações basilares referentes à inserção da Matemática no currículo, visando à superação do binômio máquina e produtividade, assinala que a organização do currículo escolar tradicional a partir da justaposição das disciplinas, sem nenhum processo de penetração mútua, é apontada como responsável por uma formação fragmentada, baseada na dissociação e no esfacelamento do saber. 


\begin{abstract}
A abordagem interdisciplinar, em contrapartida, junto a uma postura crítica e a um questionamento constante do saber, traria possibilidades de um enriquecimento por meio de novos enfoques, ou da combinação de perspectivas diferentes, incentivando a busca de caminhos alternativos que não apenas aqueles dos saberes já adquiridos, instituídos e institucionalizados (PIRES, 2004, p. 33).
\end{abstract}

Assim, a interdisciplinaridade é percebida por especialistas como a interação necessária entre as diversas disciplinas no processo de organização e desenvolvimento curricular, a partir de uma análise crítica da realidade e da percepção do papel que o educador tem nesta realidade. Essa interação pode ir da simples comunicação de ideias à integração mútua de conceitos diretores da epistemologia, da terminologia, da metodologia, dos procedimentos, dos dados e da organização referentes ao ensino e à pesquisa.

A interdisciplinaridade tem assumido posição central nas discussões da Pedagogia, sendo vista como palavra de ordem para uma ação pedagógica efetiva da escola.

De acordo com Santomé (1998), a interdisciplinaridade pode ser compreendida como uma tentativa para corrigir os erros e as infecundidades geradas pela ciência excessivamente compartimentada, ou seja, como uma proposta progressista e desafiadora, visto que o avanço do conhecimento sempre teve relação com novos questionamentos e reformulação de antigos conceitos em novas perspectivas. O olhar interdisciplinar pode induzir especialistas a se sensibilizarem por perspectivas nunca levantadas nos seus domínios e a se sentirem desafiados a rever seus conceitos, tendo como referência de análise novos conhecimentos adquiridos no intercâmbio com outras disciplinas.

Para o autor, repensar o currículo e sua ressignificação em uma sociedade pedagógica representa analisar alguns pressupostos que norteiam a sociedade atual. Por conseguinte, impõe-se superar uma concepção de currículo isolado, descontextualizado e fragmentado e partir para uma compreensão de nexos que possibilitam a sua construção com base na realidade.

Um reposicionamento do currículo escolar diante de uma postura interdisciplinar propicia uma intervenção educativa dialógica, aberta e ampla, que possibilita o protagonismo como exercício na prática pedagógica, uma maior abertura do canal de comunicação entre os atores sociais que constroem o currículo, maior possibilidade de trabalho, análise e interpretação dos saberes/conhecimentos culturais.

Uma perspectiva interdisciplinar do conhecimento, a partir de uma apreensão ampla da realidade, proporcionará a inocorrência de um "currículo de turista", em que, segundo Santomé (1998), a informação sobre comunidades silenciadas, marginalizadas, oprimidas e 
sem poder é apresentada de maneira deformada, com grande superficialidade, centrada em episódios descontextualizados, e passa a ser contemplada de uma perspectiva distante, como algo que não tem a ver com cada uma das pessoas que se encontra na sala de aula.

Portanto, um “currículo integrado" (SANTOMÉ, 1998) pode ser entendido como uma compreensão global do conhecimento e como a promoção de maiores parcelas de interdisciplinaridade na sua construção. Essa integração ressaltaria a unidade que deve existir entre as diferentes disciplinas e formas de conhecimento nas instituições escolares.

\section{A interdisciplinaridade no contexto da Educação Matemática}

Ao analisarmos trabalhos no âmbito da Educação Matemática sobre a temática, percebemos que grande parte dessas produções reduz-se a apresentar experiências didáticas em sala de aula - com pouca, ou nenhuma, discussão epistemológica ou metodológica sobre a abordagem interdisciplinar no ensino de Matemática. Em grande maioria, aduzem apenas atividades didáticas que articulam a Matemática com outras áreas de conhecimento; porém, tais experiências revelam contextualizações iniciais do conteúdo, nas quais mantêm, em sua essência, práticas fragmentadas e que pouco contribuem para que o aluno perceba o sentido do conhecimento matemático na realidade, por vezes concreta, outras abstrata (mundo das ideias) - premissa inicial e essencial da interdisciplinaridade no ensino de Matemática.

No contexto deste trabalho, vislumbramos a interdisciplinaridade como uma exigência dada por uma sociedade repleta de saberes/conhecimentos que foram fragmentados em nome da ciência moderna para o entendimento da realidade antropossocial e natural. Para tanto, na busca de uma reaproximação destes saberes/conhecimentos diante do necessário e urgente entendimento da realidade a partir de uma ótica de superação de um paradigma cartesiano, o quebra-cabeça precisa ser remontado para uma visão, sempre multirreferencial, do mundo complexo.

A reconstrução da realidade dar-se-á a partir de redescobrimento de outros saberes que vão além daqueles instituídos como verdadeiros e mais importantes pela Ciência na modernidade, mas que coexistem na percepção da interação cognoscível do ser humano nos mundos sociocultural e natural.

Com isso, não há uma negação da necessidade de especialização ou fragmentação do conhecimento em vários momentos para seu processo de evolução, conforme apontado 
anteriormente, mas há uma necessidade de não se perder o foco do todo que dá sentido àquele fragmento.

Esses argumentos nos remetem a reflexões didático-pedagógicas no contexto do currículo escolar, visto que há necessidade de se tratar, em momentos do processo educativo, os conteúdos escolares disciplinarmente, atentando-se, contudo, para uma reconstrução do todo.

Para que ocorra de fato uma abordagem interdisciplinar da Matemática no Ensino Médio e na Educação Profissional, acreditamos necessário que a organização do trabalho pedagógico na escola aconteça de maneira coletiva, participativa e democrática. Assim, professores podem vislumbrar com outros professores perspectivas de tratamento dos conceitos além das fronteiras das disciplinas que refletem na formação disciplinar dos professores.

Desse modo, neste artigo defendemos que uma integralização efetiva da EPTNM com o Ensino Médio ocorrerá com a interdisciplinaridade como eixo central na organização do trabalho pedagógico. Para tanto, compreendemos, a partir das leituras e interpretações feitas até o momento, que o ensino de Matemática na EPTNM pode materializar-se a partir de uma prática pedagógica coletiva na escola que perpassa pela sua organização na dimensão macro e em nível curricular.

Defendemos ainda, fundamentados em Tomaz e David (2011), que uma prática interdisciplinar se efetiva na Matemática a partir de uma abordagem dos conteúdos considerando temáticas transversais - norteadoras da ação pedagógica dos professores. Tomamos, como exemplo, um curso Técnico em Informática, em que o tema inclusão digital poderia ser motriz para o seu desenvolvimento curricular, em que o ensino de Matemática tomasse corpo a partir dessa temática em articulação com os demais componentes curriculares - ressaltamos que isso só se torna possível tendo em vista a gestão coletiva e colaborativa do currículo.

A abordagem temática é utilizada para possibilitar aos alunos desenvolver competência crítica, que pode ser desencadeada com a participação dialógica em processos educacionais. Sendo assim, tal competência crítica a ser desenvolvida pode ser considerada como um recurso a ser viabilizado por meio da participação tanto dos alunos como dos professores nos processos educacionais, reputada assim como um termo-chave da Educação Matemática Crítica (SKOVSMOSE, 2001; TOMAZ; DAVID, 2011). 
Para Skovsmose (2001), um tema deve cumprir as seguintes condições:

- Tópico conhecido dos alunos ou passível de discussão de modo que conhecimentos não matemáticos ou da vida diária dos alunos possam ser utilizados.

- Passível de discussão e de desenvolvimento em um determinado tempo em um grupo.

- Ter um valor em si próprio e não deve ser meramente ilustrativo para introduzir um novo tópico matemático teórico.

- Ser capaz de criar conceitos matemáticos, ideias sobre sistematização ou ideias sobre como ou onde se usa Matemática.

- Desenvolver algumas habilidades matemáticas.

- Privilegiar a concretude social em detrimento da concretude no sentido físico.

A tematização pressupõe desenvolvimento de um tema por meio da investigação. No âmbito escolar, a investigação não necessariamente significa lidar com problemas muito sofisticados, mas sim com questões interessantes e ainda sem respostas (PONTE; BROCARDO; OLIVEIRA, 2006).

As atividades de investigação matemática possibilitam a interação na sala de aula, favorecendo o desenvolvimento das referidas atividades, proporcionando ricas oportunidades de aprendizagem para o aluno. Tomaz e David, ao defenderem esta ideia, apontam que:

Para isso, é preciso que o aluno seja colocado a explorar e formular questões, fazer conjecturas, testar e reformular questões, justificar e avaliar resultados. Uma atitude investigativa apresenta, basicamente, três fases: introdução da situação-problema; realização da investigação (individualmente, em grupos menores ou com toda a turma) e discussão dos resultados (TOMAZ; DAVID, 2011, p. 22).

No entanto, quando há temáticas mais amplas e de natureza não matemáticas, as investigações podem ser desenvolvidas por meio de modelagem matemática.

A modelagem matemática no contexto da Educação Matemática tem sido foco de muitos estudos nos últimos anos. Em termos genéricos, alguns autores apontam-na como a aplicação da Matemática em outras áreas de conhecimento, porém tal definição apresenta certa limitação teórica, dando a ideia de que qualquer atividade se caracteriza como modelagem matemática. Outras vezes, a modelagem matemática é compreendida nos parâmetros da Matemática Aplicada, expressas em esquemas explicativos em que a principal dificuldade diz respeito aos quadros de referências postos pelo contexto escolar possivelmente, os esquemas explicativos, oriundos da Matemática Aplicada, apresentam-se 
como prescritivos sobre a atividade dos alunos, os quais são avaliados em termos do que falta para chegarem ao uso adequado deles (BARBOSA, 2004).

Nesse sentido, salientamos a necessidade de reflexão sistemática da modelagem matemática na perspectiva do contexto escolar e no âmbito da Educação Matemática. Concordamos com Barbosa (2004, p. 2) ao afirmar que tal reflexão "não significa uma separação da Matemática Aplicada, com a qual a Educação Matemática tem forte intersecção, mas sim a singularização do objeto no campo da Educação Matemática”.

Embasados em Silveira e Ribas (2004), acreditamos que os fatores que justificam a inclusão da modelagem matemática no currículo escolar, em específico de Educação Profissional, são: motivação, facilitação e envolvimento de alunos e professores no processo educativo; compreensão do papel sociocultural da Matemática e de sua utilização nas diferentes áreas do conhecimento, bem como de sua importância para formação profissional diante do mundo do trabalho; desenvolvimento de habilidades gerais de exploração/investigação; desenvolvimento do raciocínio, lógico e dedutivo em geral, que, consequentemente, implica a formação de cidadão crítico e transformador de sua realidade.

Concordamos com Barbosa, quando o autor enfatiza o papel sociocultural da modelagem matemática no processo de formação do aluno.

Com essa perspectiva, creio que Modelagem pode potencializar a intervenção das pessoas nos debates e nas tomadas de decisões sociais que envolvem aplicações da matemática, o que me parece ser uma contribuição para alargar as possibilidades de construção e consolidação de sociedades democráticas (BARBOSA, 2004, p. 2).

A modelagem oferece condições sob as quais os alunos protagonizam-se em um ambiente de aprendizagem, na qual os alunos investigam, por meio da Matemática, situações da realidade problematizadas. Barbosa (2001) acrescenta que o papel do professor na modelagem matemática se torna mais compartilhado e não de detentor e transmissor do saber, mas sim de quem está na responsabilidade direta da condução das atividades em uma posição de partícipe.

O desenvolvimento de uma atividade de modelagem matemática envolve algumas etapas fundamentais: (i) escolha de um tema central a ser desenvolvido pelos alunos; (ii) recolher dados que possam ajudar a levantar hipóteses com objetivo de elaborar problemas, conforme interesse dos grupos de alunos; (iii) seleção de variáveis essenciais envolvidas nos problemas e formulação de hipóteses; (iv) sistematização de conceitos que serão utilizados na resolução dos modelos; (v) a interpretação analítica da solução; (vi) dependendo do objetivo, 
fazer a validação dos modelos, confrontando os resultados obtidos com os dados coletados. Segundo Biembengut (1997), esses procedimentos podem ser agrupados em três etapas divididas em seis subetapas, a saber:

1) Interação:

(a) Reconhecimento da situação (problema)

(b) Familiarização com o assunto a ser modelado (pesquisa)

2) Matematização:

(a) Formulação do problema (hipóteses)

(b) Resolução do problema em termos de modelo

3) Modelo matemático:

(a) Interpretação da solução - validação

Barbosa (2004) aponta que o ambiente de aprendizagem da modelagem pode se configurar por meio de três níveis, em que os alunos são convidados a indagar e/ou investigar, por meio da Matemática, situações oriundas de outras áreas da realidade:

- Nível 1 - trata da problematização de algum episódio real: a partir das informações qualitativas e quantitativas apresentadas no texto da situação, o aluno desenvolve a investigação do problema proposto.

- Nível 2 - apresentação de um problema aplicado: os dados são coletados pelos próprios alunos durante o processo de investigação.

- Nível 3 - tema gerador: os alunos coletam informações qualitativas e quantitativas, formulam e solucionam o problema.

\section{Considerações finais}

Vimos que as Diretrizes Curriculares Nacionais para a Educação Profissional de Nível Técnico (BRASIL, 1999b) estabelecem que "a educação profissional, integrada às diferentes formas de educação, ao trabalho, à ciência e à tecnologia, objetiva garantir ao cidadão o 
direito ao permanente desenvolvimento de aptidões para a vida produtiva e social". Para tanto, visando atingir tal objetivo, o documento estabelece, no seu artigo 3. ${ }^{\circ}$, os princípios norteadores da Educação Profissional de nível técnico, dentre eles, no inciso IV, dispõe a "interdisciplinaridade" - deixando claro que os referidos princípios complementam os estabelecidos pela Lei de Diretrizes e Bases da Educação Nacional (BRASIL, 1996). Por sua vez, as Diretrizes Curriculares Nacionais para o Ensino Médio (BRASIL, 1999a) também apontam a interdisciplinaridade como elemento essencial, junto à contextualização, para construção de uma pedagogia de qualidade.

$\mathrm{Na}$ revisão da literatura constatamos que há fortes argumentos na defesa de que o encontro da Matemática com outras ciências na prática pedagógica e educacional pode ajudar o estudante a construir uma visão de mundo menos fragmentada e mais articulada, desenvolvendo a capacidade de raciocinar e usar a Ciência como elemento de interpretação e intervenção da realidade. Nessa linha de raciocínio, a abordagem interdisciplinar se coloca como essencial para a formação dos profissionais técnicos.

Neste trabalho, pretendeu-se compreender a interdisciplinaridade como norteadora de currículos da EPTNM, visando a uma possível formação coerente com as reais demandas do mundo do trabalho. O conhecimento especializado é necessário, mas não suficiente para o entendimento dos mundos físico e social, pois ele não é capaz de estabelecer por si só as interações com os outros sistemas.

Contudo, as conclusões decorrentes de nossa investigação revelam muitas dificuldades na promoção de articulações entre os diversos componentes curriculares do curso na modalidade da EPTNM. Essas dificuldades são geradas pela própria organização do trabalho pedagógico e pela estrutura de gestão do trabalho escolar do IFSP, em que não há espaços de articulação entre os professores nas diversas áreas, nem uma perspectiva de trabalho colaborativo. Constatamos em nossa investigação que os espaços para estudos, planejamentos e avaliações curriculares são escassos e, quando existem, as discussões ficam restritas a uma perspectiva disciplinar entre próprias áreas.

Retomando o objetivo do nosso estudo - discutir as potencialidades de tratamento interdisciplinar da Matemática na formação dos alunos da EPTNM, considerando aspectos formativos inerentes à laboralidade e à formação geral de nível médio -, percebemos que nesse nível de ensino há uma precariedade no trabalho pedagógico com a Matemática, observando que os currículos prescrevem uma formação interdisciplinar e contextual nos 
currículos dos cursos técnicos e de Ensino Médio, a qual deve atender as finalidades destes e as da formação técnica dos futuros egressos. Entretanto, vislumbra-se uma incoerência ao se defrontar esses currículos prescritos com os currículos da instituição estudada - o IFSP.

$\mathrm{Na}$ prescrição curricular para a EPTNM, parece-nos visível a necessidade de elaboração de mais documentos agregando discussões específicas por áreas, os quais poderiam tornar-se suportes para a ação docente. Ou seja, recomendamos a elaboração de documentos curriculares, no âmbito de currículos apresentados aos professores, que contribuam para refletir sobre sua ação no contexto da sua disciplina. No caso concreto da Matemática, tais documentos abordariam a construção de referenciais específicos para seu ensino com propostas de atividades peculiares ao seu processo de ensino-aprendizagem e que angaria como pressuposto pedagógico. É nesse sentido que vislumbramos uma boa possibilidade de abordagem interdisciplinar da Matemática tratada a partir de tematizações transversais, viabilizada pela modelagem matemática.

Consideramos ainda que a ação pedagógica centrada na interdisciplinaridade seja um incentivo para a construção de uma escola participativa e decisiva na formação social do aluno e nas suas relações com o mundo do trabalho. Para as escolas da EPTNM, tomar a interdisciplinaridade como subsídio para um projeto educacional pode contribuir para a busca de qualidade na formação de cidadãos plenos. E as investigações sobre Modelagem, no nosso entendimento, oferecem elementos para esse fim.

Voltamos à questão institucional ligada à necessidade premente de abertura no interior das escolas para que professores possam estudar, discutir, avaliar a qualidade dos conteúdos trabalhados, procedimentos de ensino, avaliação, programas, ou seja, tudo o que faz parte do trabalho pedagógico na sua totalidade, inclusive o estudo e debate de cunho teórico. Para tanto, é preciso implementar de fato a concepção de formação permanente, que, segundo Alves,

Vemos que para a superação da fragmentação dos fenômenos, que nos levam a interpretações parciais, é necessário partir rumo ao pensar de múltiplas formas para a solução de problemas, é preciso criatividade, curiosidade, saber trabalhar em equipe, aceitar ideias divergentes e diferentes e compreender que enquanto vivos estivermos, estaremos aptos a aprender coisas novas (ALVES, 2010, p. 118).

Sempre é conveniente destacar que essa formação continuada dos professores dos cursos de EPTNM deve estar proposta na perspectiva do desenvolvimento profissional e com superação da tendência de tratamento instrumental da Matemática nos cursos para as 
disciplinas técnicas, perdendo-se os aspectos antropossociais da Matemática na Educação Básica preconizada por educadores matemáticos - a etnomatemática do mundo do trabalho.

\section{Referências}

ALVES, A. Contribuições de uma prática docente interdisciplinar à matemática do ensino médio. 2010. 172 f. Tese (Doutorado em Educação: Currículo) - Pontifícia Universidade Católica de São Paulo, São Paulo, 2010.

BARBOSA, J. C. Modelagem matemática: concepções e experiências de futuros professores. 2001. 253 f. Tese (Doutorado em Educação Matemática) - Instituto de Geociências e Ciências Exatas, Universidade Estadual Paulista, Rio Claro, 2001.

BARBOSA, J. C. Modelagem matemática: o que é? por quê? como? Veritati, Salvador, n. 4, p. 73-80, 2004.

BIEMBENGUT, M. S. Qualidade de ensino de matemática na engenharia: uma proposta metodológica e curricular. 1997. 305 f. Tese (Doutorado em Engenharia de Produção e Sistemas) Universidade Federal de Santa Catarina, Florianópolis, 1997.

BRASIL. Lei $\mathrm{n}^{\circ}$ 4024, de 20 de dezembro de 1961. Lei de diretrizes e bases da educação nacional. p. 1-17. Disponível em: <http://www.planalto.gov.br/ccivil_03/leis/14024.htm>. Acesso em: 25 mar. 2014.

BRASIL. Lei $n^{\circ} 5692$, de 11 de agosto de 1971. Lei de diretrizes e bases para o ensino de $\mathbf{1}^{\circ}$ e $2^{\circ}$ graus. p. 1-14. Disponível em: <http://www.planalto.gov.br/ccivil_03/leis/15692.htm>. Acesso em: 25 mar. 2014.

BRASIL. Constituiçãa. Constituição da República Federativa do Brasil: promulgada em 5 de outubro de 1988. Contêm as emendas constitucionais posteriores. Brasília, DF: Senado, 1988.

BRASIL. Lei $\mathrm{n}^{\circ}$ 9394, de 20 de dezembro de 1996. Lei de diretrizes e bases da educação nacional. p. 1-27. Disponível em: <http://www.planalto.gov.br/ccivil_03/leis/19394.htm>. Acesso em: 25 mar. 2014.

BRASIL. Resolução CNE/CEB no $\mathbf{0 3}$, de 30 de junho de 1998: Institui as diretrizes curriculares nacionais para o ensino médio. Brasília: CNE/CEB. 1999a.

BRASIL. Resolução CNE/CEB no 04, de 08 de novembro de 1999: Institui as diretrizes curriculares nacionais para a educação profissional de nível técnico. Brasília: CNE/CEB. 1999b.

BRASIL. Parâmetros curriculares nacionais: Ensino Médio. Brasília: Ministério da Educação, 1999c.

BRASIL. Resolução CNE/CEB no 01, de 03 de fevereiro de 2005: Atualiza as diretrizes curriculares nacionais definidas pelo Conselho Nacional de Educação para o ensino médio e para a educação profissional técnica de nível médio às disposições do Decreto $n^{-0}$ 5.154/2004. Brasília: CNE/CEB. 2005. 
BRASIL. Resolução CNE/CEB no 04, de 27 de outubro de 2005: Inclui novo dispositivo à Resolução CNE/CEB 1/2005, que atualiza as diretrizes curriculares nacionais definidas pelo Conselho Nacional de Educação para o ensino médio e para a educação profissional técnica de nível médio às disposições do Decreto nº 5.154/2004. Brasília: CNE/CEB. 2005.

BRASIL. Resolução CNE/CEB no 04, de 16 de agosto de 2006: Altera o artigo 10 da Resolução CNE/CEB nำ 3/98, que institui as Diretrizes Curriculares Nacionais para o ensino médio. Brasília: CNE/CEB. 2006.

BRASIL. Resumo técnico do censo escolar 2010. Brasília: INEP, 2010. Disponível em: <http://minilink.es/sry >. Acesso em: 25 mar. 2014.

BRASIL. Sondagem especial da CNI, Brasília, Ano 9, n. 2, abr. 2011. Disponível em: <http://minilink.es/srx >. Acesso em: 25 mar. 2014.

CARLOS, J. G. Interdisciplinaridade no Ensino Médio: desafios e potencialidades. 2007. 171 f. Dissertação (Mestrado em Ensino de Ciências) - Universidade de Brasília, Brasília, 2007.

D’AmBrosiO, U. Sociedade, cultura, matemática e seu ensino. Educação e Pesquisa, São Paulo, v. 1, n. 31, p. 99-120, jan.-abr. 2005.

FAZENDA, I. C. A. Integração e interdisciplinaridade no ensino brasileiro: efetividade ou ideologia? São Paulo: Loyola, 1996.

FAZENDA, I. C. A. Interdisciplinaridade: um projeto em parceria. São Paulo: Edições Loyola, 2002.

FAZENDA, I. C. A. Interdisciplinaridade-transdisciplinaridade: visões culturais e epistemológicas. In: FAZENDA, I. C. A. (Org.). O que é interdisciplinaridade? São Paulo: Cortez, 2008. p. 17-28.

FAZENDA, I. C. A. Interdisciplinaridade: história, teoria e pesquisa. São Paulo: Editora Papirus, 2011.

GONÇALVES, H. J. L. A educação profissional e o ensino de matemática: conjunturas para uma abordagem interdisciplinar. 2012. 173 f. Tese (Doutorado em Educação Matemática) - Pontifícia Universidade Católica de São Paulo, São Paulo, 2012.

JAPIASSU, H. Interdisciplinaridade e patologia do saber. Rio de Janeiro: Imago, 1976.

MACHADO, N. J. Educação: projeto e valores. São Paulo: Escrituras Editora, 2000.

MANGINI, F. N. R.; MIOTO, R. C. T. A interdisciplinaridade na sua interface com o mundo do trabalho. Revista Katálysis, Florianópolis, v. 12, n. 2, p. 207-215, jul.-dez. 2009. Disponível em: <http://www.scielo.br/pdf/rk/v12n2/10.pdf>. Acesso em: 25 mar. 2014.

PAVIANI, J. Disciplinaridade e interdisciplinaridade. In: PIMENTA, C. Interdisciplinaridade, humanismo, universidade. Porto (Portugal): Campo das Letras, 2004. p. 15-57.

PIRES, C. M. C. Formulações basilares e reflexões sobre a inserção da matemática no currículo visando à superação do binômio máquina e produtividade. Educação Matemática Pesquisa, São Paulo, v. 6, n. 2, p. 29-61, jul. 2004. 
POMBO, O. Contribuições para um vocabulário sobre interdisciplinaridade. In: POMBO, O.; LEVY, T.; GUIMARÃES, H. (Org.). A interdisciplinaridade: reflexão e experiência. Lisboa: Texto, 1994. p. 92-97.

PONTE, J. P.; BROCARDO, J.; OLIVEIRA, H. Investigações matemáticas na sala de aula. Belo Horizonte: Autêntica, 2006.

RIVAS, N. P. P. Currículo de ciências e formação do professor. São Paulo: USP, 2005. (Teias do saber.) Metodologia de ensino de disciplinas da área de ciências da natureza, atemática e suas tecnologias do Ensino Médio: física, química e biologia. Disponível em: 〈http://minilink.es/r1s >. Acesso em: 25 mar. 2014.

SACRISTAN, J. G. O currículo: uma reflexão sobre a prática. Porto Alegre: Artmed, 2000.

SANTOMÉ, J. T. Globalização e interdisciplinaridade: o currículo integrado. Porto Alegre: Artes Médicas, 1998.

SILVEIRA, J. C.; RIBAS, J. L. D. Discussões sobre modelagem matemática e o ensinoaprendizagem. 2004. Disponível em: <http://www.somatematica.com.br/artigos/a8>. Acesso em: 25 mar. 2014.

SKOVSMOSE, O. Educação matemática crítica: a questão da democracia. São Paulo: Papirus, 2001.

TOMAZ, V. S.; DAVID, M. M. M. S. Interdisciplinaridade e aprendizagem da matemática em sala de aula. Belo Horizonte: Autêntica, 2011.

Submetido em Abril de 2013. Aprovado em Agosto de 2013. 